\title{
Design of Over/Under Voltage Protection Relay using Arduino Uno for FREEDM System
}

\author{
Mohamed. F. Kotb, Magdi El-Saadawi, and Eman H. El-Desouky
}

\begin{abstract}
This paper presents a new design for over/under voltage $(\mathrm{OV} / \mathrm{UV})$ protection scheme using Arduino microcontroller. The protection scheme is designed to protect the solid-state transformer (SST) branch of a Future Renewable Electric Energy Delivery and Management (FREEDM) system. It is used as backup protection for the instantaneous, momentary and temporary voltage fluctuation of distribution medium voltage loop. Very simple, user-friendly software and hardware simulators are created to represent a branch of the FRREDM network with the designed OV/UV relay. A software program is formulated using c-code through Proteus software package and easily integrated to the hardware circuit. The designed microcontroller monitors the network voltage and the $O V / U V$ relay energies in case that its value exceeds a preset limit according to IEEE 1159. To validate and prove the effectiveness of the proposed system, different tests are performed for both software and hardware simulators at instantaneous, momentary and temporary OV/UV operation conditions. The results are compared with IEEE 1159 standard values and shows fine and high accuracy.
\end{abstract}

Index Terms-FREEDM, Over Voltage Relay, Undervoltage Relay, Arduino Uno controller.

\section{INTRODUCTION}

Overvoltage can arise due to disconnecting large loads (especially nonlinear loads), connecting capacitor banks, occurring of line to earth fault, unplanned operation of grid resources and lightening and static charges. If the voltage regulation and/or control is not capable to face these problems, electronic devices instantly can be subjected to catastrophe and will lead to equipment insulation degradation or failure if OV continued or repeated. The reactive power output from a capacitor will rapidly rise where it proportional to the square of voltage. A repetitive OV situations will lead to capacitor damage. The undervoltage can arise as a result of the reverse actions cause OV. UV situation will lead to increasing heat loss in motors due to increasing of drawn current, electronic devices may stop and the reactive power delivered from capacitor banks will be reduced. If UV persists for a long time (more than $1 \mathrm{~min}$.), the motors controllers will deenergize causes motors to stop [1], [2]. The voltage fluctuation will affect lighting intensity of incandescent and discharge lighting lamps [3].

The SST in a FREEDM system represents the interface between AC medium voltage network and low voltage AC/DC microgrid, it is considered one of the most important elements in FREEDM system. Because of the wide effects subjected to SST (composite device contains semiconductor),

Published on October 29, 2018

M. F. Kotb is with the Department of Electrical Engineering, Faculty of Engineering, Mansoura University, 35516 Mansoura, Egypt (e-mail: mohamadfawzi@gmail.com) its limited over/under voltage tolerances and the shortage of the monitoring and control nearby system, OV and UV protection scheme became mandatory [4-8]. SST can be put in danger because of internal fault, lightening surge, switching transients, LV short circuits and unbalanced/no ideal load [9-11].

The main objective of the protection system is to protect SST from the faults occurred in the grid and vice versa and protect MV network from the faults in LV microgrids and vice versa.

As per IEEE Std 1159 [1], the OV and UV can be categorized as per its duration short or long. For short duration, it is classified as instantaneous $(0.5$ - 30 cycles $)$, momentary ( 30 cycles $-3 \mathrm{secs}$ ) and temporary ( $3 \mathrm{secs}-1 \mathrm{~min}$ ). The OV magnitude for the three mentioned short duration classifications sequentially are: (1.1-1.8 pu), (1.1-1.4 pu) and (1.1-1.2 pu). The UV magnitude for the three categories are: (0.1- $0.9 \mathrm{pu})$.

Great efforts exerted by researchers to protect the electric equipment against $\mathrm{OV}$ and UV trying to achieve selectivity, sensitivity, security, safety, speed, reliability, low losses and cost [9]. It is a big challenge to achieve most of these objectives.

Microcontroller-based relay is proposed by $[12,13]$ to protect transformer by designing a simulation circuit using Proteus. Circuit is designed for Arduino controller by measuring the $\mathrm{AC}$ voltage and converting $\mathrm{AC}$ analog voltage to $\mathrm{DC}$ voltage by means of rectifier and filter and protected by Zener diode [14]. Prototype scheme includes overvoltage protection using Arduino Uno for single phase terminal system is proposed to disconnect load elements [15].

In this paper a proposed scheme is introduced based on Arduino microcontroller and deals with both OV/UV limits according to IEEE standards. The proposed scheme is simulated by the use of Proteus software; The three classes; instantaneous, momentary, and temporary of OV/UV relays are addressed. The using of $\mathrm{C}$-code in the software enables selecting the relays mode with precise relay settings. To validate the proposed scheme, a practical module is designed and tested in the laboratory. The results from the software simulator and hardware module are compared with respect to the IEEE standard characteristics and shows soundness of the proposed system. The practical and simulated results reflect the reliability, security, accuracy and flexibility of the proposed protection scheme.

M. El-Saadawi is with the Department of Electrical Engineering, Faculty of Engineering, Mansoura University, 35516 Mansoura, Egypt (e-mail m_saadawi@mans.edu.eg)

E. H. El-Desouky is with the North Delta Electricity Distribution Co. Mansoura (Egypt) (e-mail: Eman.el desouky@ yahoo.com) 


\section{PRoblem Statement}

The SST branch components; SST, loads and renewable sources are subjected to many operational conditions that affect the voltage behavior. Due to the load variations or faults, a large decrease or increase of voltage can be produced which may damage the electronic equipment's. To face these server problems a reliable secure, accurate and calibrated protection over/under voltage protection scheme is proposed in this study as shown in Figure 1.

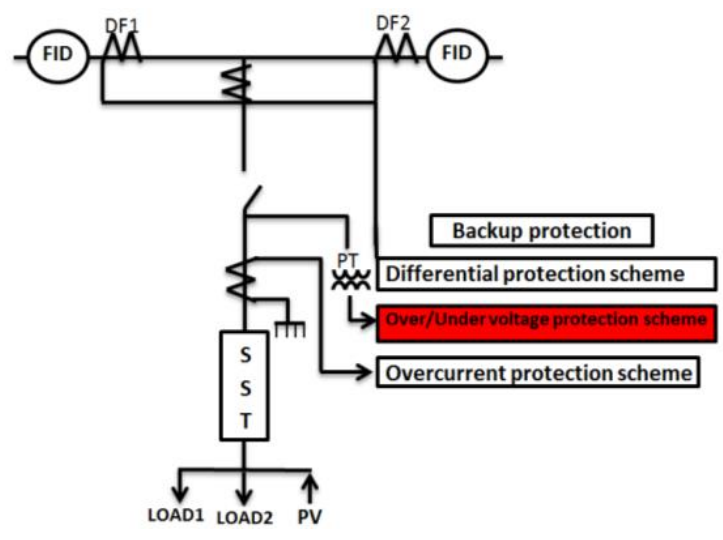

Fig.1: Backup protection units

\section{Proposed TeChNique}

The FREEDM system distribution loop, the SST branch and the proposed OV /UV protection scheme is represented by a circuit as shown in Figure 2.

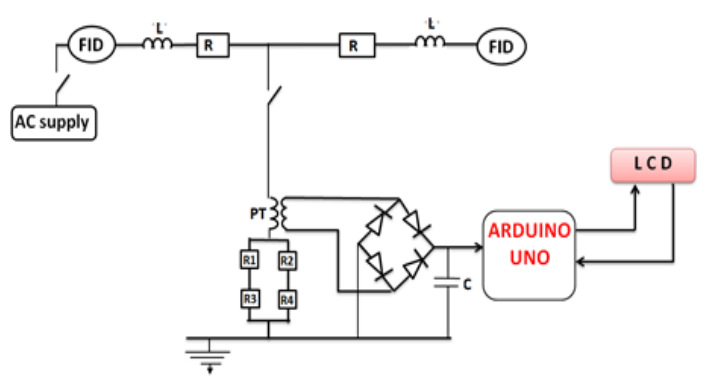

Fig.2: Schematic Diagram of over/under voltage protection scheme for FREEDM system

The circuit is implemented as software simulator and hardware practical circuit. The FREEDM system voltage is represented by an a.c. supply. The line/cable between the two Fault Isolation Devices (FIDs) are represented as resistances and reactances. The actual SST branch voltage is stepped down to smaller values using potential transformer (PT) as voltage signal to the proposed $\mathrm{OV} / \mathrm{UV}$ relay. This voltage signal is converted to analog d.c. value to feed Arduino (A0) using full wave rectifier bridge. Arduino microcontroller is utilized by downloading software program designed through Proteus package using $\mathrm{C}$ language. A software is created to satisfy OV/UV protective relay according to the typical characteristics of power system electromagnetic phenomena (instantaneous, momentary or temporary) as per IEEE 159 standard which are required to protect FREEDM system. The bridge output d.c. value represents the main a.c. supply. The practical variations in a.c. system are achieved by controlling bridge outgoing d.c. through the Arduino as per mode/set points. If the set point is reached, the controller sends a trip signal to the circuit breaker and the state of OV /UV (instantaneous, momentary or temporary) will appear on the LCD. The OV/UV protective relays function is designed using C-code program including modes/set points and simulated via Proteus software according to the flow charts shown in Figures 3 and 4.

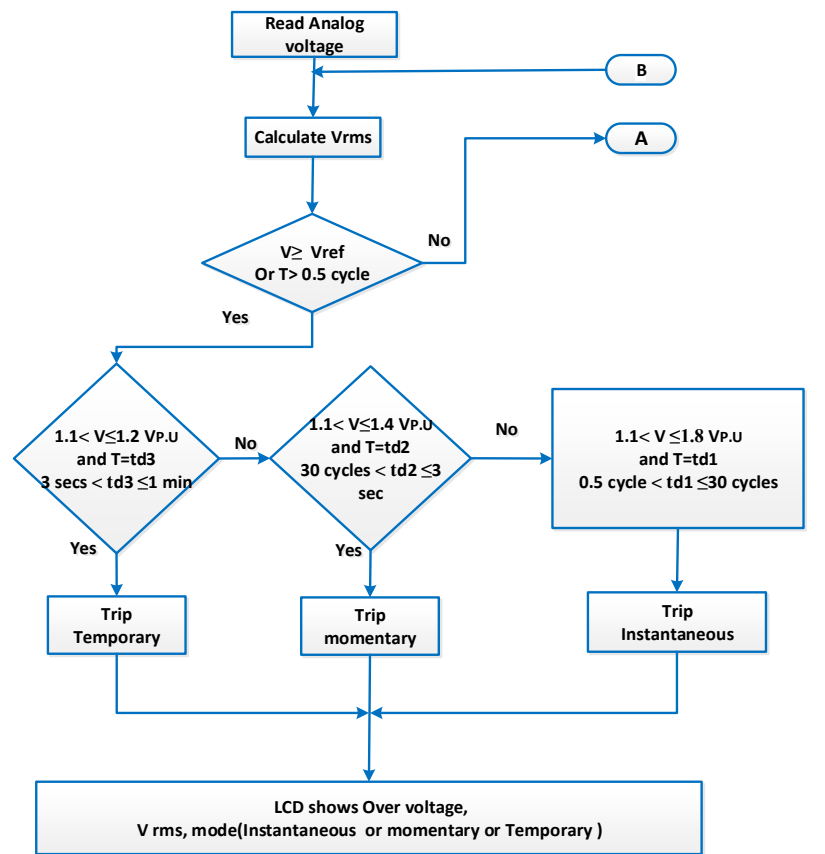

Fig.3: Proposed Over Voltage Simulator Relay Based on Arduino Uno Controller Flow Chart

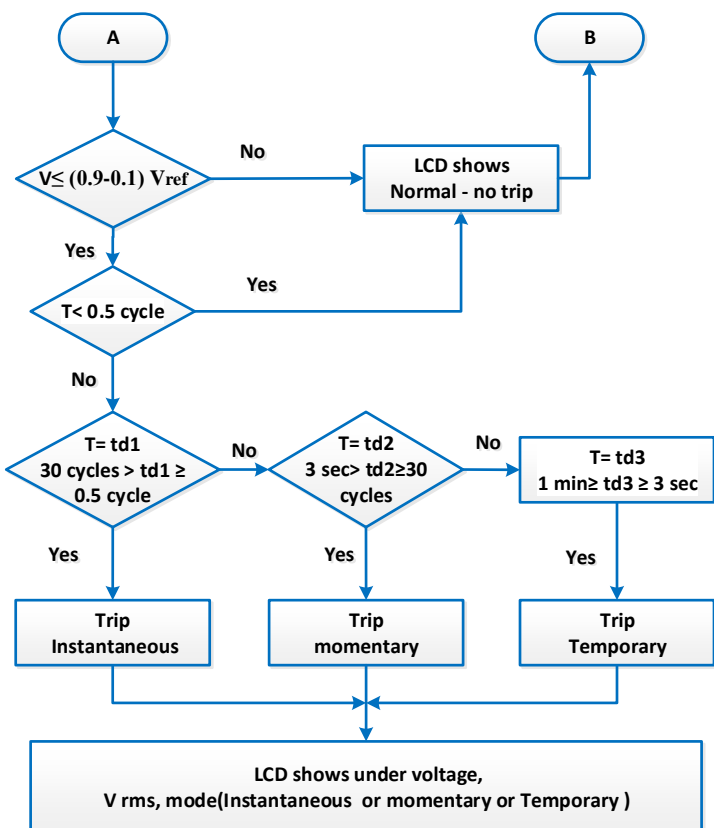

Fig.4: Proposed Under Voltage Simulator Relay Based on Arduino Uno Controller Flow Chart

The same designed software is uploaded to hardware Arduino microcontroller circuit in Figure 5. The simulation software microcontroller is tested for all possible OV/UV conditions to assess and validate the effectiveness of proposed method. The OV/UV hardware microcontroller is tested for only momentary condition because of the unavailability of the element required for other conditions. 


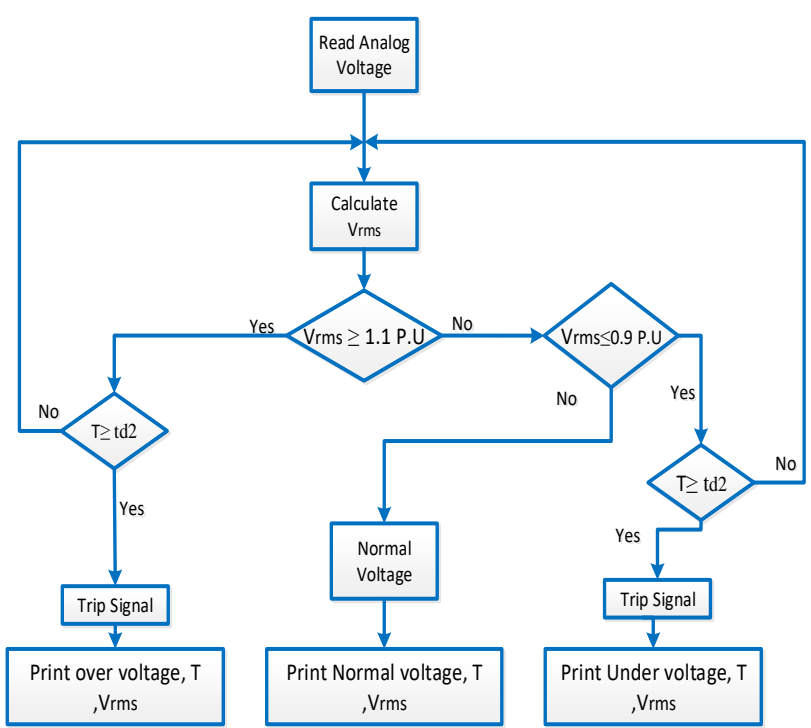

Fig.5: Practical circuit logic proposed for Under/Over Voltage Relay Based on Arduino Uno Controller Flow Chart

\section{CiRCUIT DESIGN}

The main components' data of the prototype circuit diagram indicated in Figure 2 are given in Table 1.

TABLE I: MAIN COMPONENTS DATA OF PROTOTYPE CIRCUIT

\begin{tabular}{cccc}
\hline \hline Element & Data & Element & Data \\
\hline Arduino Uno & $\begin{array}{c}\text { Arduino Uno } \\
\text { REV3 }\end{array}$ & $\begin{array}{c}\text { R, R1, R2, R3, } \\
\text { R4, R9, R10 }\end{array}$ & $10 \mathrm{~K} \Omega$ \\
\hline LCD & $\begin{array}{c}\text { Model } \\
\text { ALLBHA 4*20 }\end{array}$ & $\mathrm{R} 5$ & $1 \mathrm{~K} \Omega$ \\
\hline Relay & $\begin{array}{c}\text { 5-volt, coil } \\
\text { resistance 240 } \Omega\end{array}$ & $\mathrm{RV} 1$ & 5K $\Omega$, Linear \\
\hline RV3 & 1K $\Omega$, linear & $\mathrm{RV} 2$ & $30 \mathrm{~K} \Omega$ \\
\hline $\begin{array}{c}\text { Step-dawn } \\
\text { transformer }\end{array}$ & $220 / 5$ volt & OP-Amp 1,2 & LM741 \\
\hline
\end{tabular}

The main circuit contains ac supply, stepdown transformer, rectification circuit, Arduino controller, Solid state relay and LCD liquid crystal display as per the following details:

a- A.C. input supply with 220 ac volt.

b- Step down transformer 220/6 volt.

c- Rectification Circuit: It can be achieved using full wave bridge as in Figure 2 or two Op-Amp as on Figure 6. The first amplifier adds the input a.c. voltage with 2.5 d.c voltage and the second one inverts the wave before feeding it to the input pin of Arduino. The added d.c. to the input is subtracted from the calculated RMS value by the software code before injecting to the relay. The two op-amp method is more accurate with minor harmonics other than the rectification bridge method.

d- Arduino controller: Arduino is an open source electronic device easy to use hardware and software. Arduino is a good and sheep type of controller. Its programming language is very easy and achieves all the OV/UV relay proposal requirements. It compares the input signal comes from d.c. circuit with the preset values fed to the software program. If the voltage value exceeds the limits for the specified times as per the IEEE 1159, a trip signal is initiated and isolates the main circuit breaker.

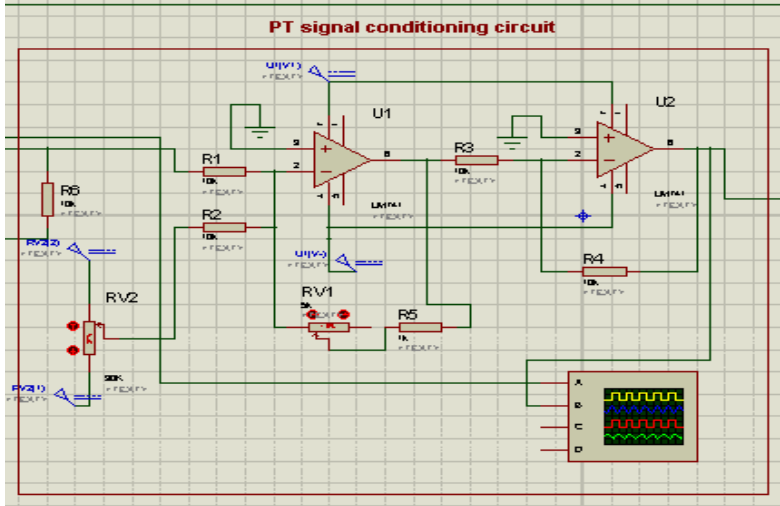

Fig.6: Measuring a.c. using op-amp method

e- Solid state relay: It is a relay module used for Arduino and microcontrollers. It is a 5 volt, $10 \mathrm{~A}, 2$ channels relay interface board. It is used for controlling many applications of controllers and other devices with greater currents. The pins are marked on the PCB as following: GND connected to zero voltage pin, IN1 control the relay number 1, active low, IN2 control the relay number 2, active low and VCC connected to 5 volts this pin. The relay has high current AC $250 \mathrm{~V}, 10 \mathrm{~A}, \mathrm{DC} 30 \mathrm{~V}, 10 \mathrm{~A}, 2$ LEDS to indicate when relay is on, Operated with $3 \mathrm{~V}$ or $5 \mathrm{~V}$ devices, Opto isolation circuitry and PCB size $50 * 45 \mathrm{~min}$.

f- LCD liquid crystal display: LCD screen is an electronic display module and have a wide range of control applications. The $16 * 2$ LCD display is the basic screen module and is very popular use in different devices and control circuits. The main reasons of using LCDS are economical, have no displaying limitations and easily programmable. There are many types of LCD located the library of simulation software.

\section{Proposed Circuit Simulation And Results}

Two scenarios are simulated for OV/UV relay when it is instantaneous, momentary and temporary conditions.

\section{A. Scenario 1: Proposed OV relay simulation}

In this scenario, the relay is selected as an overvoltage type shown by Figure 7 . The value of voltage is changed by using of potentiometer to specific percentage as per IEEE 1159 for instantaneous, momentary, temporary conditions till the relay operates, isolates the supply power source and records the duration on the LCD.

The simulation results are tabulated in Table 2. The table explains different increment percentage and the tripping time. The results show an accurate tripping time compared with IEEE 1159.

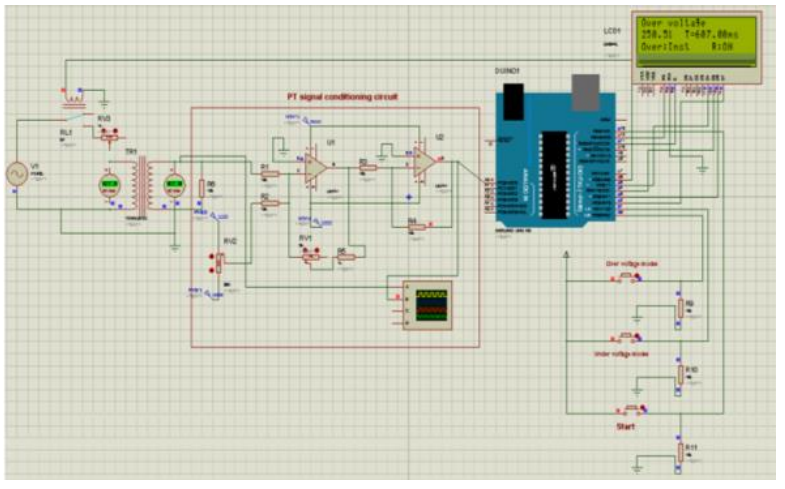

(a) Instantaneous OV Relay simulation 


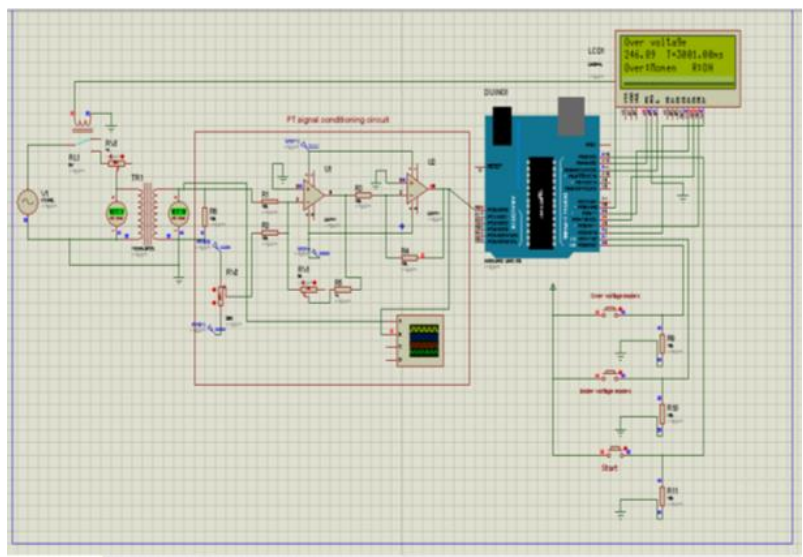

(b) Momentary OV Relay simulation

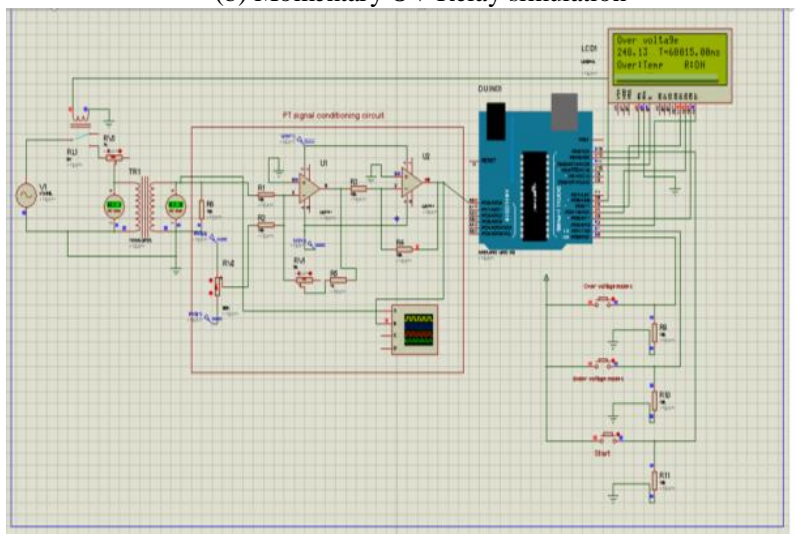

(c) Temporary OV Relay simulation

Fig.7: Typical schematic diagram for the Proposed OV relay at different OV conditions

(a) Instantaneous, (b) Momentary and (c) Temporary

TABLE II: OV RELAY CHARACTERISTIC RESULTS FOR 220 V SUPPLY

\begin{tabular}{ccccc}
\hline \hline $\begin{array}{c}\text { Type of OV } \\
(\text { P.U) }\end{array}$ & $\begin{array}{c}\text { Voltage } \\
\text { Increment } \\
\%\end{array}$ & $\begin{array}{c}\text { Measured } \\
\text { voltage }(\mathrm{V})\end{array}$ & $\begin{array}{c}\text { Trip } \\
\text { Time } \\
(\mathrm{ms})\end{array}$ & $\begin{array}{c}\text { IEEE 1159 } \\
\text { Standard } \\
\text { duration }\end{array}$ \\
\hline & 110 & 242 & 606 & \\
Instantaneo & 111 & 244 & 607 & $0.5-30$ cycles \\
us (1.1-1.8) & 150 & 330 & 607 & \\
& 180 & 396 & 607 & \\
\hline & 110 & 242 & 3007 & \\
Momentary & 112 & 246 & 3001 & 30 cycles -3 \\
$(1.1-1.4)$ & 120 & 262 & 3005 & secs \\
& 130 & 286 & 3005 & \\
\hline Temporary & 110 & 240 & 60015 & \\
$(1.1-1.2)$ & 115 & 253 & 60000 & 3 secs-1 min \\
\end{tabular}

\section{B. Scenario 2: Proposed UV relay simulation}

1- Select the type of relay as undervoltage type as in Figure 8.

2- Change the value of voltage by using of potentiometer to specific percentage as per IEEE 1159 for instantaneous, momentary and temporary undervoltage conditions till the relay operates, isolates the supply power source and records the duration on LCD.

The different decrement voltage percentage and the tripping time results are illustrated in Table 3 which shows an accurate tripping time compared with IEEE 1159.

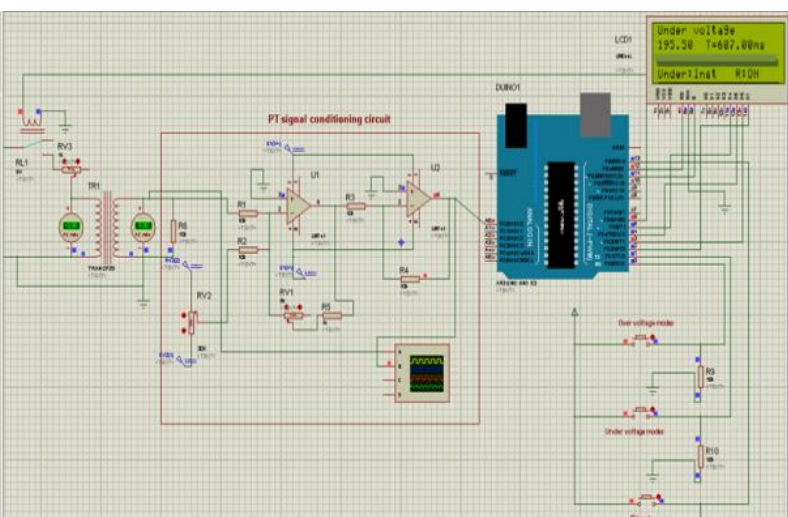

(a) Instantanous UV Relay simulation

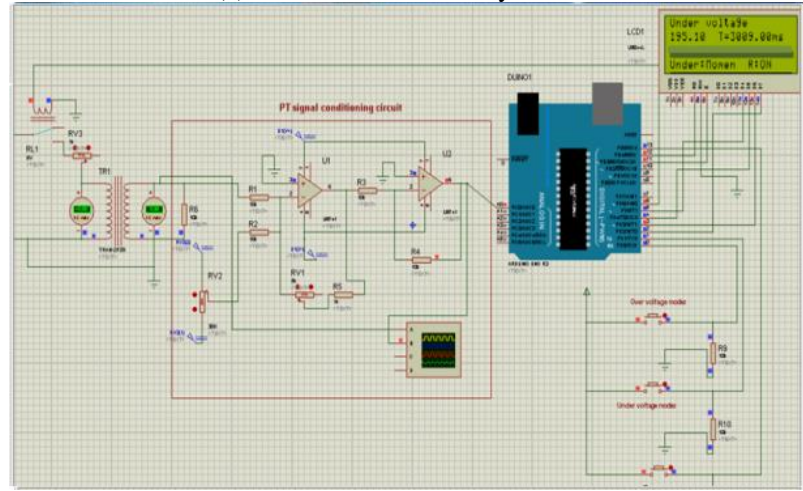

(b) Momentary UV Relay simulation

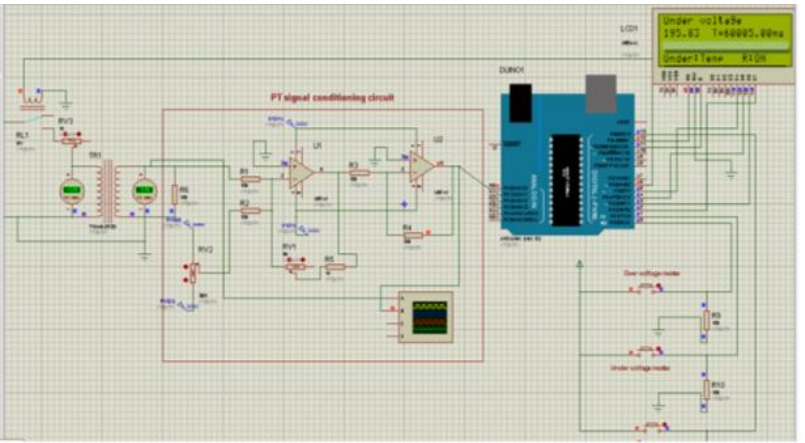

(c) Temporary UV Relay simulation

Fig.8: Typical schematic diagram for the

Proposed UV relay at different UV conditions. (a) Instantaneous, (b) Momentary and (c) Temporary 
TABLE III: UV RELAY CHARACTERISTIC RESULTS FOR 220 V SUPPLY

\begin{tabular}{ccccc}
\hline \hline $\begin{array}{c}\text { Type of UV } \\
(\mathrm{P} . \mathrm{U})\end{array}$ & $\begin{array}{c}\text { Voltage } \\
\text { decrement } \\
\%\end{array}$ & $\begin{array}{c}\text { Measured } \\
\text { voltage } \\
(\mathrm{V})\end{array}$ & $\begin{array}{c}\text { Trip } \\
\text { time } \\
(\mathrm{ms})\end{array}$ & $\begin{array}{c}\text { IEEE 1159 } \\
\text { Standard } \\
\text { duration }\end{array}$ \\
\hline \multirow{3}{\text{Instantaneous}}{} & 90.9 & 200 & 617 & $0.5-30$ \\
$0.1-0.9$ & 90 & 195 & 607 & cycles \\
& 80 & 176 & 619 & \\
\hline & 55 & 120 & 618 & \\
Momentary & 90 & 198 & 3011 & \\
$0.1-0.9$ & 88 & 195 & 3009 & 30 cycles - \\
& 80 & 176 & 3007 & 3 secs \\
& 55 & 120 & 3008 & \\
\hline & 90 & 198 & 60000 & \\
Temporary & 88 & 195.2 & 60005 & 3 sec-1 min \\
& 80 & 176 & 60000 & \\
\hline
\end{tabular}

\section{Practical Circuit Implementation}

A practical circuit of the proposed OV/UV relay using Arduino Uno microcontroller elements described in Table 1 and Figure 2, is shown in Figure 9. Single phase 300-watt motor and 60-watt lamp represents network load. The OV relay is tested for $+10 \%$ increase and UV is tested for $-10 \%$ decrement both as momentary type ( 3 sec-30 cycle).

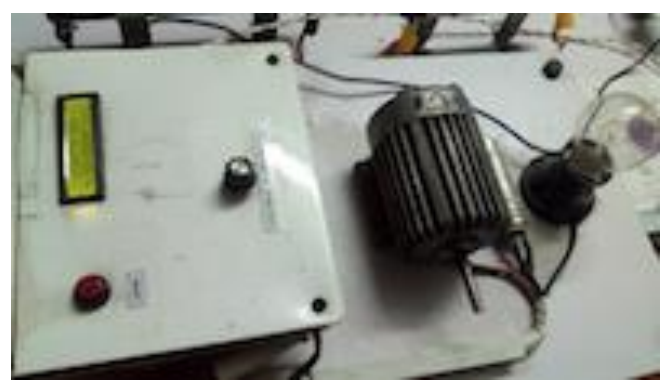

Fig.9: Practical circuit layout

Table 4 indicates the practical circuit results which is matched with the IEEE 1159 limits and proves the proposed design.

TABLE IV: OV/UV RELAY PRACTICAL CIRCUIT IMPLEMENTATION RESULTS
\begin{tabular}{cccc}
\hline $\begin{array}{c}\text { Measured } \\
\text { voltage }\end{array}$ & $\begin{array}{c}\text { Voltage } \\
\%\end{array}$ & Trip time & State \\
\hline 220 & 100 & - & Normal - No trip \\
\hline 235 & 107 & - & Normal - No trip \\
\hline 245 & 114 & 1.5 & OV - trip \\
\hline 250 & 136 & 1.5 & OV - trip \\
\hline 215 & 98 & - & Normal - No trip \\
\hline 205 & 93 & - & Normal - No trip \\
\hline 187 & 85 & 1.5 & UV - trip \\
\hline
\end{tabular}

\section{CONCLUSION}

An OV/UV relay design was proposed using Arduino Uno microcontroller. Software program has been created through Proteus package using $\mathrm{C}$ language. Software simulator and hardware circuit for the proposed OV/UV relay that can be utilized for FREEDM system has been developed and tested to ensure its effectiveness. The simulator software simulates instantaneous, momentary and temporary OV/UV relay. The hardware circuit was fabricated using Arduino microcontroller board, uploaded with the created program and furnished with inputs and outputs to monitor and protect a motor load. The OV/UV relay momentary condition behavior was tested and verified using the practical circuit. The results obtained from both software simulator and practical circuit are compatible with IEEE 1159 recommended limits. The results reflect the strength of the design of OV/UV relay scheme and also support the reliability of three types of relays based on microcontrollers.

\section{REFERENCES}

[1] IEEE Std 1159'TM-2009, "IEEE Recommended Practice for Monitoring Electric Power Quality"

[2] P. Manish, C. Antara and S. Snigdha,"Hardware Implementation of Over Voltage and Under Voltage Protection", International Journal of Innovation Research in Electric, vol.3, issue 6, June 2015.

[3] IEEE Std 141-1993, "IEEE Recommended Practice for Electric Power Distribution for Industrial Plants"

[4] A. Huang, "FREEDM System - A Vision for the Future Grid," IEEE Power and Energy Society General Meeting, Providence, USA, 25-29 July 2010, pp.1-4

[5] N. Sharma,"Novel Directional Protection Scheme for the FREEDM Smart Grid System," M. Sc. Thesis submitted to Arizona State University, August 2015.

[6] P. Mandava,"Design and Development of Protection Schemes for FREEDM Smart Grid Systems," M. Sc. Thesis submitted to Arizona State University, December 2014.

[7] O. Vodyakho, "Solid-State Fault Isolation Devices: Application to Future Power Electronics-Based Distribution Systems," IET Electric Power Application, Vol. 5, Issue 6, July 2011, pp. 521 - 528.

[8] M.F. Kotb, M. El-Saadawi, E.H. El-Desouky,"Protection Coordination Optimization for Future Renewable Electric Energy Delivery and Management (FREEDM) System", Journal of Electrical Engineering JEE, USA, vol. 6 (2018), pp. $161-176$

[9] T. Guillod, F. Krismer, J. W. Kolar,"Protection of MV Converters in the Grid: The Case of MV/LV Solid-State Transformers", IEEE Journal of Emerging and Selected Topics in Power Electronics, vol. 5, Issue 1, March 2017, pp. 393 - 408

[10] C. Zhao, D. Dujic, A. Mester, J. K. Steinke, et al.,"Power Electronic Traction Transformer - Medium Voltage Prototype," IEEE Trans. on Ind. Electron., vol. 61, no. 7, Jul. 2014, pp. 3257-3268.

[11] T. Guillod, J. E. Huber, G. Ortiz, A. De, et al., "Characterization of the Voltage and Electric Field Stresses in Multi-Cell Solid-State Transformers," in Proc. of the IEEE Energy Conversion Congress and Expo. (ECCE), Sep. 2014, pp. 4726-4734.

[12] R. Arpit, S. Jeet, D. Anuradha, "Simulation of Power Transformer Protection Using Microcontroller Relay" International Journal of Scientific Engineering and Technology, vol.4, Issue.6, 01 June 2015, pp: 352-355.

[13] N. Adil and Naveed A.," Protection of distribution transformer using Arduino Platform” Science International Journal, vol. 27, issue 1, 2015, pp. 403-406.

[14] "AC voltage measurement using Arduino", available at: https://circuits4you.com/2016/05/13/arduino-ac-voltage/ , accessed at 2-9-2018.

[15] B. Sourin, Herjee, S. Priyam, M. Sarbojit, S. Victor, and S. Sourav, "A Novel Approach to Overvoltage and Overcurrent Protection of Simple Single Phase Two Terminal Systems Utilizing Arduino Uno", International Journal of Electrical Engineering, vol. 10, No. 1 (2017), pp. 97-110.

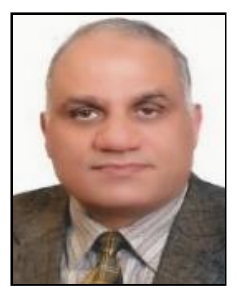

Mohamed F. Kotb was born in Monofia, Egypt, on 1960. He graduated from Mansoura University. $\mathrm{He}$ received M.Sc. and $\mathrm{PhD}$ Degree from Mansoura University in 1989 and 1998 respectively. $\mathrm{He}$ is a member of Electrical Department in faculty of Engineering, Mansoura University. He is interested in The Electrical Power System Analyses and application researches. He has wide experience with industry applications, consultations and International Training. Dr. Mohamed is member in IEEE. His $E$ mail is: mohamadfawzi@gmail.com. 


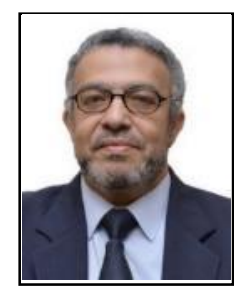

Magdi M. El-Saadawi was born in Mansoura

Egypt in 1959. He received his B.Sc. and M.Sc.

from Mansoura University, Egypt in 1982 and

1988, respectively, and his Ph.D. from Warsaw

University of Technology in 1997. He was a

teaching assistant at El-Mansoura University from

1983-1992. From 1997, he was a staff member of

the Electrical Engineering Department, Mansoura

University, and has been a professor since May

2011. His fields of interest include, renewable energy, power system analysis, and AI applications in power systems. His e-mail is(m_saadawi@mans.edu.eg.

Eman H. El-Desouky received her B.Sc.in 2008 from Arab Academic for science and technology "AAST", department of electrical and control engineering. Also, completed her M.Sc. in 2015 from Electric department at faculty of engineering, Tanta university. She is interested in power system protection and control as well as renewable energy sources management. She is working in North Delta Electricity Distribution Co. Mansoura (Egypt). Her e-mail is (Eman.el desouky@ yahoo.com) 